Case Report

\title{
A case report of androgen receptor inhibitor therapy in recurrent high-grade serous ovarian cancer
}

This article has an addendum. Addendum in: Oncotarget. 2022; 13:982-982.

\author{
Sewanti Limaye ${ }^{1}$, Prashant Kumar ${ }^{2,3,4}$, Ramya Pragya ${ }^{1}$, Janani Sambath ${ }^{3,4}$, \\ Darshana Patil2, Ajay Srinivasan², Sachin Apurva², Navin Srivastava², Sanket Patil², \\ Revati Patil2, Vineet Datta ${ }^{2}$, Dadasaheb Akolkar ${ }^{2}$ and Rajan Datar ${ }^{2}$ \\ ${ }^{1}$ Kokilaben Dhirubhai Ambani Hospital and Medical Research Institute, Mumbai, Maharashtra, India \\ ${ }^{2}$ Datar Cancer Genetics Limited, Nasik, Maharashtra, India \\ ${ }^{3}$ Institute of Bioinformatics, International Technology Park, Bangalore, Karnataka, India \\ ${ }^{4}$ Manipal Academy of Higher Education, Manipal, Karnataka, India \\ Correspondence to: Sewanti Limaye, email: sewanti.limaye@gmail.com \\ Prashant Kumar, email: prashant.kumar@datarpgx.org
}

Keywords: high grade serous ovarian cancer; androgen receptors; bicalutamide

Received: July 16, $2020 \quad$ Accepted: October 27, 2020

Published: November 17, 2020

Copyright: @ 2020 Limaye et al. This is an open access article distributed under the terms of the Creative Commons Attribution License (CC BY 3.0), which permits unrestricted use, distribution, and reproduction in any medium, provided the original author and source are credited.

\section{ABSTRACT}

Ovarian cancer is common gynaecological malignancy and a leading cause of death among women. Despite the advances in treatment strategies, majority of patients present with recurrence after first- or second-line treatment. Targeted therapy that has proven to be effective in other advanced or metastatic solid tumors have also demonstrated its efficacy in ovarian cancer. Recent studies have shown that the androgen receptor (AR) signalling is involved in pathogenicity and progression of cancer. Current observations suggest AR could be a potential target in managing the disease. In this case report we present a patient with high grade serous ovarian cancer (HGSOC) with multiple relapses with excellent disease control on AR inhibition with bicalutamide.

\section{INTRODUCTION}

Ovarian cancer is the third most common gynaecological malignancy and is the fifth leading cause of death in women. Due to lack of proper screening and early diagnostics, $70 \%$ of the patients are diagnosed with advanced stage ovarian cancer. The standard treatment for ovarian cancer includes surgery and combination treatment with carboplatin and paclitaxel. Many patients respond to the first line therapy; however $60-70 \%$ and $80-85 \%$ of women with residual disease $<1 \mathrm{~cm}$ and large-volume residual disease show recurrence [1]. Lack of proper molecular stratification and resistance to the conventional chemotherapy account for higher mortality.

The presence of hormone receptors such as androgen receptors (AR), progesterone receptors (PR) and estrogen receptors (ER) has been positively correlated with progression of many cancers including ovarian cancer [2-4]. The ER, PR and AR pathways are involved in regulating the signalling pathways such as cell-proliferation, apoptosis, epithelial to mesenchymal transition, cell migration and invasion. The role of AR in female includes muscle strength and volume, erythropoietin production, bone formation/growth, and differentiation/maturation of bone marrow stem cells. The role of AR in tumorigenesis and tumor progression of breast and ovarian cancer of women has been previously reported $[5,6]$. It has been reported that the expression of $\mathrm{AR}$ in ovarian cancer is more related to the cancer subtype than the FIGO staging [7]. Toledo et al. reported that the serous ovarian cancer have more prevalence of AR expression than the non-serous ovarian cancer [8]. AR directed therapy is an active area of interest in management of different cancers and much effort is ongoing to target AR and AR-related pathways. Current evidences from the reported studies show selection of appropriate patients based on AR expression, AR polymorphism, and activity of AR downstream targets could be useful to optimize the clinical outcome $[9,10]$.

In this study, we report a case of recurrent highgrade serous ovarian cancer patient who had a durable response to AR targeted therapy designed based on 
Encyclopedic Tumor Analysis (ETA) (Exacta ${ }^{\circledR}$ ) [11] which is an integrative, multi-analyte test and includes molecular analysis of comprehensive gene expression, DNA mutation profiling, chemosensitivity assay, immunohistochemistry and immunocytochemistry on tumor tissue and blood.

\section{CASE PRESENTATION}

A 57-year-old female with a prior history of hypertension, was diagnosed with Stage IIIC high-grade serous ovarian carcinoma (HGSOC) nearly 5 years ago. The patient received neo-adjuvant chemotherapy with paclitaxel and carboplatin every 3 weeks for 3 cycles. A repeat scan done post 3 cycles showed partial response to treatment and patient underwent a cytoreductive surgery at an outside center. The surgical pathology was consistent with Stage IIIC disease noted earlier with lack of good response to carboplatin and paclitaxel given neoadjuvantly. Hence treatment was switched to gemcitabine, cisplatin and bevacizumab during adjuvant therapy for 3 cycles. A repeat scan done post completion of treatment showed complete resolution of disease.

The patient remained disease free but had a relapse with the PET scan showing FDG avid lesions in the liver and pouch of Douglas after 3 years. The patient was started on second-line chemotherapy with gemcitabine, cisplatin and bevacizumab. However, bevacizumab was discontinued after first dose as the patient developed internal bleeding in the operative bed. Next two cycles of chemotherapy were continued with gemcitabine and cisplatin alone without bevacizumab. A CT scan done post completion of 3 cycles of treatment showed response to therapy. The patient did not continue any further chemotherapy at this time due to toxicity issues. No PARP inhibitor was offered due to $B R C A$ negative status on germline testing at the time. The patient developed progressive disease after 9 months and underwent a second surgery with excision of the vaginal vault and the pelvic mass and omentectomy. Histopathology was suggestive of metastatic HGSOC. For the ideal therapeutic options, the sample was sent for multi-analyte Exacta ${ }^{\circledR}$ analysis.
The overview of the treatment given is summarised in (Figure 1).

The integrative, multi-analyte Exacta ${ }^{\circledR}$ test includes molecular analysis of comprehensive gene expression, DNA mutation profiling, chemosensitivity assay, immunohistochemistry and immunocytochemistry. For targeted transcriptome analysis, RNA from tumor tissue and adjacent normal tissue were used. Significant differential expressed genes were called using the following threshold: absolute log fold-change $\geq 2$ and $p$-value $<0.05$ (Figure 2). The gene expression analysis showed the expression of 6984 genes in which 1970 genes were differentially regulated when compared to adjacent normal tissue. Out of 1970 genes 957 genes were upregulated and 1013 genes were downregulated (Supplementary Table 1). Next generation sequencing analysis for mutations and amplifications of 409 oncogenes and tumor suppressor genes was carried out on the FFPE tumor tissue and cell free DNA. Tumor mutation analysis detected mutations in genes CTNNB1 (p. G34V), TP53 (p. N263fs), PKHD1 (p. R3107Q) and IGF2R (p. A1425A) mutations. Copy number alteration analysis showed a copy loss in chromosomal regions including $4 \mathrm{p}, 4 \mathrm{q}, 5 \mathrm{p}, 5 \mathrm{q}, 6 \mathrm{p}$, $7 \mathrm{p}, 10 \mathrm{q}, 11 \mathrm{p}, 12 \mathrm{q}, 13 \mathrm{q}, 17 \mathrm{p}, 17 \mathrm{q}, 18 \mathrm{q}, 19 \mathrm{p}$ and a copy gain in $7 q$ and 16p. Longitudinal mutation profiling of cell-free DNA (cfDNA) was performed for the serial monitoring of circulating tumor burden in patient. Mutation load varied in the range $0 \%$ to $0.13 \%$ until 2019 . However marginal increase in the mutational load of $0.26 \%$ and $0.56 \%$ was observed in the next follow-up samples (Figure 3). TP53 (p. A159V and p. W146fs) gene mutation was observed in cell free nucleic acid analysis and are reported to be associated with early relapse and adverse prognosis in HGSOC. She was negative for any germline mutations.

The immunohistochemistry of the tissue samples revealed strong nuclear staining for ER $(90 \%$ of tumor cells) and PR ( $80 \%$ of tumor cells); and moderate staining for AR (30\% of tumor cells) (Figure 4). Chemosensitivity assay was performed on circulating epithelial cells (CECs) isolated from peripheral blood sample and showed high and modest response to vinorelbine and temsirolimus respectively.

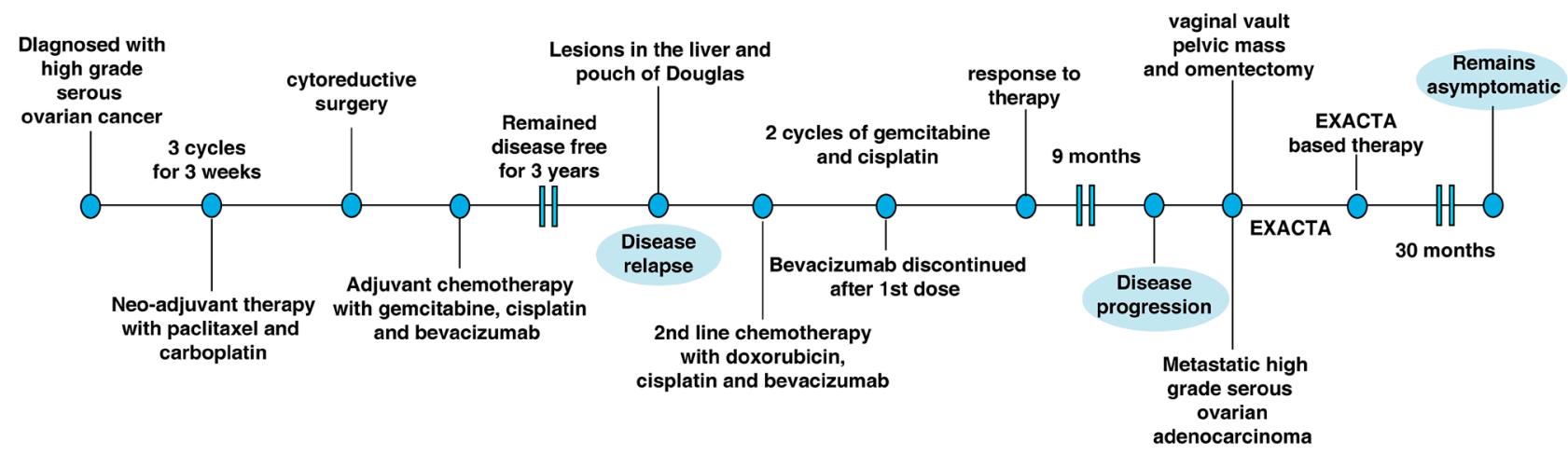

Figure 1: The clinical time line of the 57-year old female presented with high-grade serous ovarian cancer. 
Patient was then proposed treatment with Exacta $^{\circledR}$ based novel regimen with weekly injection of temsirolimus and oral therapy with tab bicalutamide $50 \mathrm{mg}$ once daily. Temsirolimus was used due to the presence of PTEN loss (10q23.2) on genomic analysis and due to chemosensitivity analysis showing response in vivo.
Bicalutamide was used due to the immunohistochemistry showing AR expression and also due to the fact that PTEN loss is known to confer resistance to aromatase inhibitor based therapy targeting the ER/PR. She was also started on supplementary treatment with quercetin and vitamin E capsules as per Exacta $^{\circledR}$ based recommendation. The

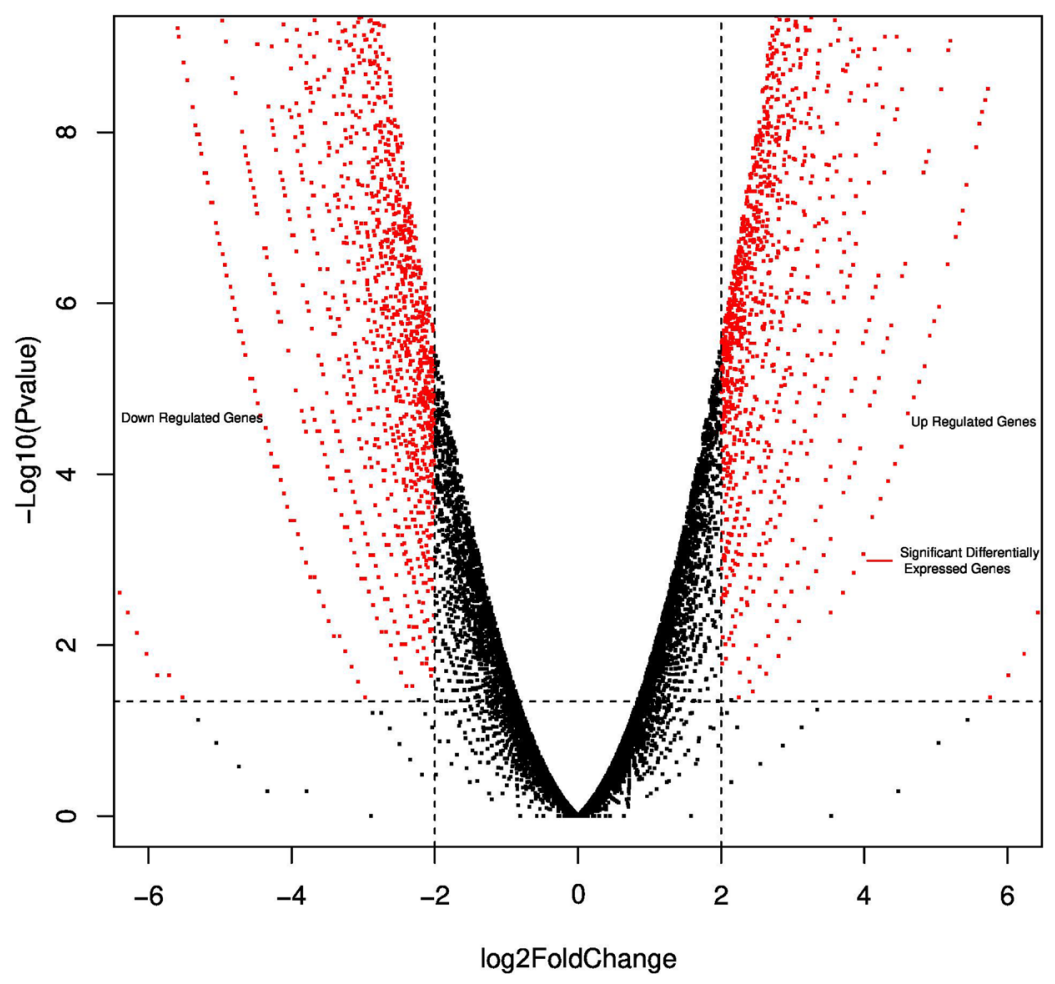

Figure 2: Volcano plot reporting $\boldsymbol{P}$ values against fold changes. The Volcano plot indicates $-\log 10(P$-value) for genes (Y-axis) plotted against their respective log 2 (fold change) (X-axis). The red dots represent significantly upregulated and downregulated Differentially Expressed Genes (DEG); black indicates no significant difference.

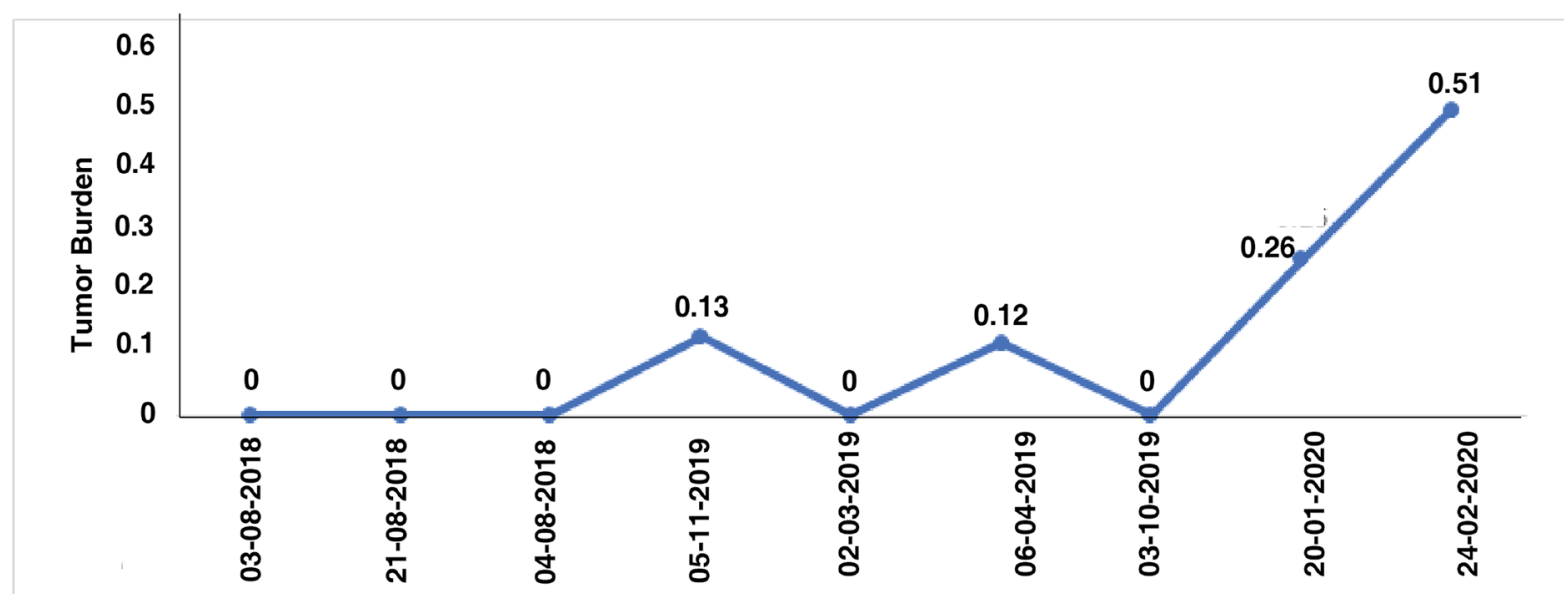

Timeline

Figure 3: Longitudinal analysis of tumor mutation burden using the number of SNVs detected in each cell free DNA samples. 
patient received 3 cycles of the combination therapy. However, temsirolimus was stopped since she started experiencing vasomotor side effects and patient was continued on tab bicalutamide $50 \mathrm{mg}$ once daily, quercetin and vitamin E. She remains with no evidence of disease and no disease relapse over the last 30 months of Exacta ${ }^{\circledR}$ guided therapy.

\section{DISCUSSION}

Ovarian cancer accounts for 295,414 new cases and 184,799 deaths around world-wide (GLOBOCAN 2018). More than $90 \%$ of the malignant cancers are of epithelial in origin and $70 \%$ of these malignant cancers belong to HGSOC [12]. The first line treatment for HGSOC includes surgery followed by combination chemotherapy. The patient presented in this study showed a relapse after the first line therapy. She developed recurrent disease two years later and since it was still considered to be platinum sensitive, the patient was treated with platinum-based combination therapy. Targeted therapy with bevacizumab a vascular endothelial growth factor (VEGF) inhibitor was added due to known added benefit in recurrent disease, however, had to be stopped due to toxicity [13]. No PARP inhibitor was offered due to $B R C A$ negative status on germline testing at the time. It is known that patients with ovarian cancer who fail two lines of therapy have very poor prognosis. An exploratory multi-analyte testing was carried out at this juncture to understand the biology of this tumor better and in an attempt to find newer therapeutic options.

Mutational status of cfDNA reflects the genetic characterization of tumor lesion. TP53 is the most frequently mutated tumour-suppressor gene in human cancer with the highest frequency of $80 \%$ in HGSOC [14]. Studies have highlighted the potential of cfDNA as diagnostic and prognostic tool for ovarian cancer and showed a relation between TP53 mutations detected in cfDNA at diagnosis and residual disease or disease progression. Various TP53 hotspot mutations can have different implications on outcome of disease and in response to chemotherapy [15]. Tumor mutation burden from cfDNA is used as an independent biomarker to assess the response to immunotherapy in many cancers [16, 17]. Elevated tumor mutation burden has shown prolonged response to immune check point inhibitors in platinum resistant ovarian cancer [18]. The present report shows marginal increase in the mutation load with long-term
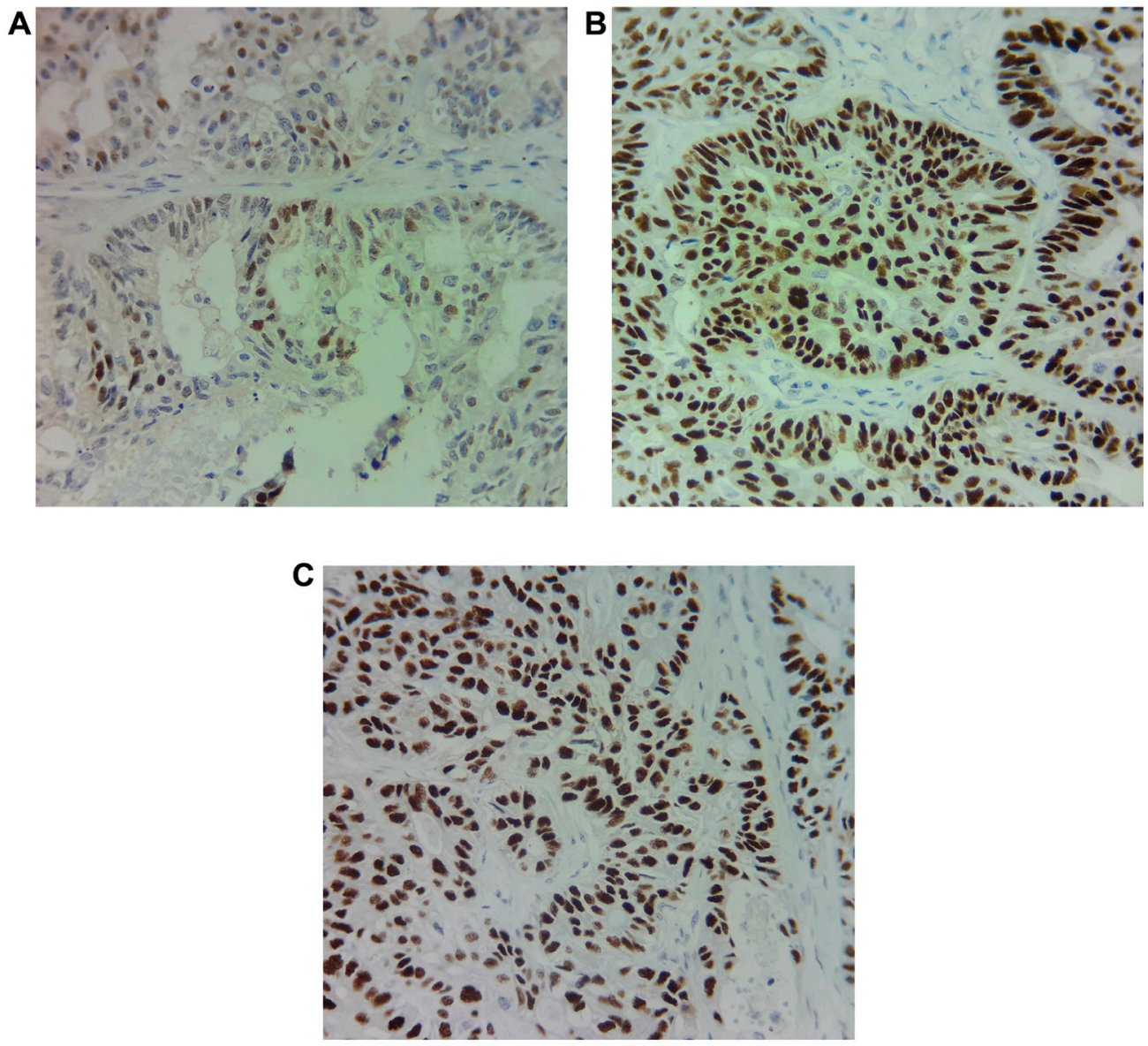

Figure 4: Immunohistochemical staining of (A) Androgen receptor (AR), (B) Estrogen receptor (ER) and (C) progesterone receptor (PR) shows $30 \%, 90 \%$ and $80 \%$ of expression respectively in the primary tumor cells. 
response to bicalutamide, an AR antagonist suggesting tumor mutation burden as biomarker to monitor the treatment response.

In the current study, we identified high expression of AR protein in the patient. AR, a steroid hormone receptor belongs to the nuclear receptor superfamily and is activated by androgen hormones. Although no specifics cut-offs are practiced, in breast cancer some studies have used at least $1 \%$ nuclear staining of any intensity (1+ to $3+$ ) as a positive AR IHC assay [19]. In a Phase II study of single agent enzalutamide in AR positive recurrent ovarian cancer $\geq 5 \%$ AR expression by IHC was considered positive [20]. The activation of AR leads to its nuclear localization and regulation of expression of genes involved in different physiological and pathological functions [21]. AR signalling has been associated with tumorigenesis and metastasis of cancers such as prostate, bladder, kidney, lung, breast, liver and ovary. Androgens have been shown to involved in cell proliferation and invasion of ovarian cancer cells suggesting targeting AR as a capable treatment choice [21, 22]. AR targeted therapies have been widely employed in breast and prostate cancers [23-25]. Bicalutamide, an AR antagonist which binds to the AR block the action of androgens. It is widely used, especially in the Asia Pacific region as targeted therapy of prostate cancer and was used here in addition to temsirolimus $[24,26]$. Temsirolimus was used due to PTEN loss seen in genomic analysis. PTEN loss is also known to confer resistance to aromatase inhibitor based therapy targeting the ER/PR. The response from bicalutamide, an AR inhibitor suggests that anti-androgen- based therapies could be an effective treatment option for AR positive ovarian cancer patients. Although the patient presented in this case showed relapse after the first line and second line therapy, the patient has now been without any relapse after being started on this Exacta ${ }^{\circledR}$ guided treatment as a result of the AR directed therapy with bicalutamide. This response is not thought to be from temsirolimus since the patient was only able to take 3 cycles of the drug due to severe toxicity issues.

In conclusion, we present a patient with advanced HGSOC with multiple relapses with moderate AR expression detected on multi-analyte Exacta $^{\circledR}$ based analysis. The higher expression of AR in the patient provides strong evidence of pathogenicity. Further, targeting AR with bicalutamide based therapy resulted in a durable response in this patient. Our result suggests targeting AR using bicalutamide as an efficient treatment strategy in AR positive HGSOC.

\section{Author contributions}

PK, SL, JS drafted the initial manuscript. NS, SA, RP performed the sequencing experiment and bioinformatics data analysis. PK, SL, JS, DA, RD carried out the data analyses and interpretations. DP, RP performed immunohistochemistry analysis. SP carried out chemo-sensitivity analysis. AS, DA, VD, RD reviewed and revised the manuscript. All authors read and approved the final version of the manuscript.

\section{CONFLICTS OF INTEREST}

Authors have no conflicts of interest to declare.

\section{FUNDING}

This research did not receive any specific grant from funding agencies in the public, commercial, or not-forprofit sectors.

\section{REFERENCES}

1. Foley OW, Rauh-Hain JA, del Carmen MG. Recurrent epithelial ovarian cancer: an update on treatment. Oncology (Williston Park). 2013; 27:288-98. [PubMed]

2. Voutsadakis IA. Epithelial-Mesenchymal Transition (EMT) and Regulation of EMT Factors by Steroid Nuclear Receptors in Breast Cancer: A Review and in Silico Investigation. J Clin Med. 2016; 5:11. https://doi. org/10.3390/jcm5010011. [PubMed]

3. Lenhard M, Tereza L, Heublein S, Ditsch N, Himsl I, Mayr D, Friese K, Jeschke U. Steroid hormone receptor expression in ovarian cancer: progesterone receptor B as prognostic marker for patient survival. BMC Cancer. 2012; 12:553. https://doi.org/10.1186/1471-2407-12-553. [PubMed]

4. van Kruchten M, van der Marel P, de Munck L, Hollema H, Arts H, Timmer-Bosscha H, de Vries E, Hospers G, Reyners A. Hormone receptors as a marker of poor survival in epithelial ovarian cancer. Gynecol Oncol. 2015; 138:634-639. https://doi.org/10.1016/j.ygyno.2015.06.032. [PubMed]

5. Rahim B, O'Regan R. AR Signaling in Breast Cancer. Cancers (Basel). 2017; 9:21. https://doi.org/10.3390/ cancers9030021. [PubMed]

6. Tworoger SS, Lee IM, Buring JE, Hankinson SE. Plasma androgen concentrations and risk of incident ovarian cancer. Am J Epidemiol. 2008; 167:211-218. https://doi. org/10.1093/aje/kwm278. [PubMed]

7. Sheach LA, Adeney EM, Kucukmetin A, Wilkinson SJ, Fisher AD, Elattar A, Robson CN, Edmondson RJ. Androgen-related expression of G-proteins in ovarian cancer. Br J Cancer. 2009; 101:498-503. https://doi. org/10.1038/sj.bjc.6605153. [PubMed]

8. de Toledo MC, Sarian LO, Sallum LF, Andrade LL, Vassallo J, de Paiva Silva GR, Pinto GA, Soares FA, Fonseca CD, Derchain SF. Analysis of the contribution of immunologically-detectable HER2, steroid receptors and of the "triple-negative" tumor status to disease-free and overall 
survival of women with epithelial ovarian cancer. Acta Histochem. 2014; 116:440-447. https://doi.org/10.1016/j. acthis.2013.09.010. [ [PubMed]

9. Vassilomanolakis M, Koumakis G, Barbounis V, Hajichristou H, Tsousis S, Efremidis A. A phase II study of flutamide in ovarian cancer. Oncology. 1997; 54:199-202. https://doi.org/10.1159/000227688. [PubMed]

10. Elattar A, Warburton KG, Mukhopadhyay A, Freer RM, Shaheen F, Cross P, Plummer ER, Robson CN, Edmondson RJ. Androgen receptor expression is a biological marker for androgen sensitivity in high grade serous epithelial ovarian cancer. Gynecol Oncol. 2012; 124:142-147. https://doi. org/10.1016/j.ygyno.2011.09.004. [PubMed]

11. Nagarkar R, Patil D, Crook T, Datta V, Bhalerao S, Dhande S, Palwe V, Roy S, Pandit P, Ghaisas A, Page R, Kathuria H, Srinivasan A, et al. Encyclopedic tumor analysis for guiding treatment of advanced, broadly refractory cancers: results from the RESILIENT trial. Oncotarget. 2019; 10:56055621. https://doi.org/10.18632/oncotarget.27188. [PubMed]

12. Reid BM, Permuth JB, Sellers TA. Epidemiology of ovarian cancer: a review. Cancer Biol Med. 2017; 14:9-32. https:// doi.org/10.20892/j.issn.2095-3941.2016.0084. [PubMed]

13. Gupta S, Nag S, Aggarwal S, Rauthan A, Warrier N. Maintenance therapy for recurrent epithelial ovarian cancer: current therapies and future perspectives - a review. J Ovarian Res. 2019; 12:103. https://doi.org/10.1186/s13048019-0579-0. [PubMed]

14. Vitale SR, Groenendijk FH, van Marion R, Beaufort CM, Helmijr JC, Dubbink HJ, Dinjens WNM, Ewing-Graham PC, Smolders R, van Doorn HC, Boere IA, Berns E, Helleman J, et al. TP53 Mutations in Serum Circulating Cell-Free Tumor DNA As Longitudinal Biomarker for High-Grade Serous Ovarian Cancer. Biomolecules. 2020; 10:415. https://doi.org/10.3390/biom10030415. [PubMed]

15. Tuna M, Ju Z, Yoshihara K, Amos CI, Tanyi JL, Mills GB. Clinical relevance of TP53 hotspot mutations in high-grade serous ovarian cancers. Br J Cancer. 2020; 122:405-412. https://doi.org/10.1038/s41416-019-0654-8. [PubMed]

16. Fenizia F, Pasquale R, Roma C, Bergantino F, Iannaccone A, Normanno N. Measuring tumor mutation burden in non-small cell lung cancer: tissue versus liquid biopsy. Transl Lung Cancer Res. 2018; 7:668-677. https://doi. org/10.21037/tlcr.2018.09.23. [PubMed]

17. Birkbak NJ, Kochupurakkal B, Izarzugaza JM, Eklund AC, Li Y, Liu J, Szallasi Z, Matulonis UA, Richardson AL, Iglehart JD, Wang ZC. Tumor mutation burden forecasts outcome in ovarian cancer with BRCA1 or BRCA2 mutations. PLoS One. 2013; 8:e80023. https://doi. org/10.1371/journal.pone.0080023. [PubMed]
18. Morse CB, Elvin JA, Gay LM, Liao JB. Elevated tumor mutational burden and prolonged clinical response to antiPD-L1 antibody in platinum-resistant recurrent ovarian cancer. Gynecol Oncol Rep. 2017; 21:78-80. https://doi. org/10.1016/j.gore.2017.06.013. [PubMed]

19. Safarpour D, Pakneshan S, Tavassoli FA. Androgen receptor (AR) expression in 400 breast carcinomas: is routine AR assessment justified? Am J Cancer Res. 2014; 4:353-368. [PubMed]

20. Grisham R, Giri D, Henson M, Iasonos A, Zhou Q, McDonnell A, Girshman J, O'Cearbhaill R, Zamarin D, Aghajanian C. 38 Phase II study of enzalutamide in androgen receptor positive $(\mathrm{AR}+)$ recurrent ovarian cancer: final results. https://doi.org/10.1136/ijgc-2019-IGCS.38.

21. Mizushima T, Miyamoto H. The Role of Androgen Receptor Signaling in Ovarian Cancer. Cells. 2019; 8:176. https://doi. org/10.3390/cells8020176. [PubMed]

22. Edmondson RJ, Monaghan JM, Davies BR. The human ovarian surface epithelium is an androgen responsive tissue. Br J Cancer. 2002; 86:879-885. https://doi.org/10.1038/ sj.bjc.6600154. [PubMed]

23. Giovannelli P, Di Donato M, Galasso G, Di Zazzo E, Bilancio A, Migliaccio A. The Androgen Receptor in Breast Cancer. Front Endocrinol (Lausanne). 2018; 9:492. https:// doi.org/10.3389/fendo.2018.00492. [PubMed]

24. Osguthorpe DJ, Hagler AT. Mechanism of androgen receptor antagonism by bicalutamide in the treatment of prostate cancer. Biochemistry. 2011; 50:4105-4113. https:// doi.org/10.1021/bi102059z. [PubMed]

25. Reichert ZR, Hussain M. Androgen Receptor and Beyond, Targeting Androgen Signaling in Castration-Resistant Prostate Cancer. Cancer J. 2016; 22:326-329. https://doi. org/10.1097/PPO.0000000000000214. [PubMed]

26. Chiong E, Murphy DG, Akaza H, Buchan NC, Chung BH, Kanesvaran R, Khochikar M, Letran J, Lojanapiwat B, Ng CF, Ong T, Pu YS, Saad M, et al. Management of patients with advanced prostate cancer in the Asia Pacific region: 'real-world' consideration of results from the Advanced Prostate Cancer Consensus Conference (APCCC). BJU Int. 2019; 123:22-34. https://doi.org/10.1111/bju.14489. [PubMed] 